\title{
Primary classical seminoma of testis with foci of signet-ring-cell morphology: A case report and review of the literature including ESMO guidelines on management of seminoma of testis
}

\author{
Anthony Kodzo-Grey Venyo, Kweku Baiden-Amissah \\ 1. Department of Urology, North Manchester General Hospital, Manchester, UK. 2. Royal Oldham Hospital Department of \\ Histopathology Oldham, UK
}

Correspondence: Anthony Kodzo-Grey Venyo. Address: North Manchester General Hospital Department of Urology, Manchester, United Kingdom. Email: akodzogrey@yahoo.co.uk.

Received: May 11, 2012

DOI : $10.5430 / j b g c . v 3 n 1 p 81$
Accepted: June 5, 2012

Online Published: December 24, 2012

URL: http://dx.doi.org/10.5430/jbgc.v3n1p81

\section{Abstract}

Background: Signet-ring-cell carcinoma is a rare variant of mucinous adenocarcinoma. Only about 3 cases of primary testicular cancer with signet-ring-cell morphology have been reported so far in the literature. There is lack of knowledge regarding the biological behaviour of this type of tumour affecting the testis. Seminoma of the testis is quite common and its biological behaviour is well known. When a classical seminoma of the testis is found to be contemporaneously associated with signet-ring-cell morphology, in view of the absence of any detailed literature on this rare clinical entity, the biological behaviour of such a tumour cannot be predicted.

Objectives: To report a case of Classical Seminoma of the testis interspersed with seminoma cells with signet-ring morphology. To review the literature on signet-ring-cell carcinomas including carcinomas of testis with signet- ring- cell morphology. To review the ESMO guidelines on management of seminoma of testis

Results: A 32-year-old man came for urology consultation 11 months after he had noticed a lump in his left testis. He had a family history of testicular cancer. A hard lump clinically suspicious of a tumour was palpable in the lower pole of his left testis. The right testis felt normal on palpation. His serum Beta HCG level was raised. He had ultra-sound scan of testis which showed bilateral microlithiasis with a tumour in the left testis but no tumour in the right testis. He underwent left radical orchidectomy and histology of the testicular tumour revealed a classical testicular seminoma with foci of signet-ring -cell morphology based upon haematoxylin and eosin staining as well as positive immunostaining for CD117 and OCT 3 / 4. Literature review revealed paucity of literature on testicular tumours with signet-ring-cell morphology.

Conclusions: There is paucity of literature on primary testicular tumours with signet-ring-cell morphology. In order to establish the biological behaviour of such tumours we would encourage pathologists and urologists to report cases of testicular tumours associated with signet-ring-cell morphology together with the long term biological behaviour of such tumours. They should also report on the percentage of testicular tumours that have signet-ring-cell morphology and their distribution whether patchy or diffuse. Ultrasound-scan of testis was required to establish the diagnosis of testicular cancer 
in the patient. Ultrasound-scan of testis is useful in the investigation of a testicular lump. Ultrasound and CT scans are also useful for the follow-up of patients with testicular cancer and microlithiasis.

\section{Key words}

Classical Seminoma, Signet-ring-cell morphology, OCT 3/4, CD117, Immunohistochemistry, Radical orchidectomy

\section{Introduction}

Signet-ring-cell is a malignant histological cell type which is predominantly seen in carcinomas. Signet ring cells have frequently been reported in association with carcinoma of stomach ${ }^{[1]}$, but signet ring cells have also been reported in carcinomas of other tissues including the prostate ${ }^{[2]}$, bladder, gallbladder ${ }^{[3]}$, breast, colon ${ }^{[4]}$, ovarian stroma ${ }^{[5,6]}$, eyelid ${ }^{[7,8]}$. There have also been occasional reports of metastatic signet ring cell carcinoma to the testis, spermatic cord and scrotum. Only about 3 cases of primary seminoma of testis with signet-ring-cell morphology have been reported in the literature. In general, a number of signet ring cell carcinomas have been reported to be associated with a worse prognosis ${ }^{[8-10]}$. We report a case of seminoma of testis associated with foci of signet-ring-cell morphology with a review of the literature.

\section{Case report}

A 32-year-old gentleman was referred by his general practitioner to be seen by the urologist because he had noticed a lump in his left testis eleven months earlier. He had noticed that the lump had been increasing in size since he first noticed the lump. He had also developed a sensation of heaviness in the left testis. He did not have any other symptom. He had a family history of testicular cancer in that his father had testicular carcinoma.

His general and systematic examinations were normal. His right testis and epididymis felt normal. The upper two-thirds of the left testis, was smooth in outline and of normal consistency and the lower one third felt hard and suspicious of malignancy.

He had a number of investigations which were reported as follows:

- $\quad$ Full blood count - normal

- Serum urea and electrolytes - normal

- Liver function tests - normal

- Serum Lactic Dehydrogenase - normal $227 \mathrm{u} / \mathrm{L}$ (normal range 123 - $243 \mathrm{u} / \mathrm{L}$ )

- Serum Human Chorionic Gonadotrophin 12 IU/L (normal range $<2$ IU/L)

- Serum Alpha feto protein - normal $2 \mathrm{KU} / \mathrm{L}$ (normal range $<10 \mathrm{KU} / \mathrm{L}$ )

- Serum Follicle stimulating Hormone (FSH) - (19 U/L High [normal range 1 - $10 \mathrm{U} / \mathrm{L}])$

- Serum Luteinising Hormone (LH) - $6 \mathrm{u} / \mathrm{L}$; (normal range $1-9 \mathrm{u} / \mathrm{L}$ )

- $\quad$ Chest X-ray - normal

He also had ultrasound scan of testes and scrotal contents which was reported as consistent with a left testicular tumour (a germ tumour / seminoma) and bilateral microlithiasis (see Figures 1 and 2).

He then underwent a trans-inguinal left radical orchidectomy and the orchidectomy specimen was sent to the pathologists for histological examination. 
Figure 1. First ultrasound-scan of testes on 6th showing bilateral microlitiasis no tumour in right testis but tumour in left testis which was reported as likely germ cell tumour/ seminoma

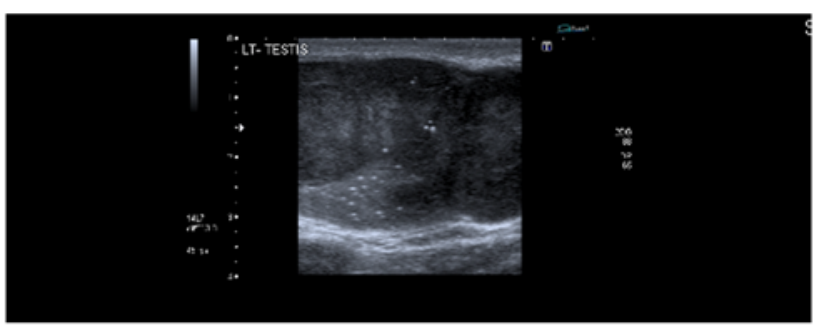

Figure 2. Ultrasound scan showing microlithiasis clearly in the right testis

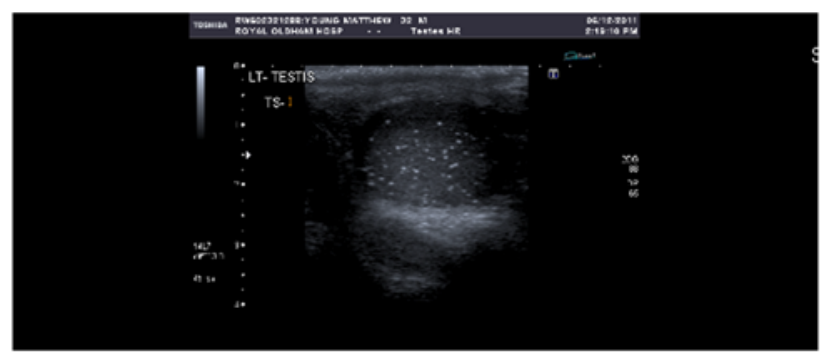

The orchidectomy specimen was subjected to macroscopic and microscopic examinations. On macroscopic examination the specimen was noted to consist of the testis with the attached spermatic cord which together weighed 79 grams. The testis, measured $70 \mathrm{~mm} \times 50 \mathrm{~mm} \times 40 \mathrm{~mm}$; the attached-cord was $65 \mathrm{~mm}$ in length and $18 \mathrm{~mm}$ in diameter. Externally the testis appeared enlarged and lobulated and on sectioning it showed lobulated nodular tan and pale brown tumour. The tumour appeared to be confined within the testis and did not breach the tunica albuginea. The cut surface showed focal areas of brownish discoloration indicative of haemorrhage. The residual normal testis at the upper aspect was up to $20 \mathrm{~mm}$ in maximum dimension. There was no evidence of infiltration of the epididymis, the rete testis or the cord.

On microscopic examination, the tumour was considered to have features of a classical seminoma. The tumour was confined to the testis and did not invade the tunica albuginea. The epididymis and the rete testis were free of tumour. There was no evidence of lymphovascular invasion. The cord and cord resection margins were also free of tumour. No nonseminomatous germ cell tumour components were present. The adjacent non-neoplastic testicular parenchyma showed a few tubules with spermatogenic atrophy and thickening of the tubular membrane. The examining pathologist concluded that the findings on examination of the left orchidectomy specimens, was consistent with that of a classical seminoma which was completely excised and consistent with stage pT1 tumour. The specimen was next sent to the Regional Oncology centre where all patients with testicular cancer are ultimately referred for review by another pathologist.

Pursuant to further microscopic examination of haematoxylin and eosin stained sections of the specimen and immunohistochemistry of the specimen by the reviewing pathologist, the ensuing supplementary report was made by the reviewing pathologist: As reported by the initial examining pathologist, the testicular tumour was a classical seminoma (see Figures 3 to 6). No non-seminomatous tumour elements were identified. The testicular tumour appeared confined to the testis with no involvement of the rete testis or paratesticular structures and there was no evidence of lympho-vascular invasion. A granulomatous reaction was seen in the tumour in places. The tumour appeared to replace most of the testis and there was atrophy and focal calcification in the small amount of residual testicular parenchyma. Focally the tumour cells showed signet ring morphology (see Figures 3 and 4), a feature which has recently been described in rare cases of classical seminoma, though this is without clinical significance. Immunohistochemistry showed that the tumour cells, including the signet ring cells, were positive with c-kit (CD117) (see Figure 6). AE1/3 and Ber H2 (CD30) were negative. OCT 3 / 4 (see Figure 5) was strongly positive. The tumour stage was pT1. The reviewing pathologist concluded that the tumour was classical seminoma, stage pT1. 
Figure 3. Haematoxylin and Eosin staining $\times 10$ Magnification

Classical Seminoma showing clear cells with prominent nucleoli admixed with lymphocytes and plasma cells. Seminoma cells with signet ring morphology are present

Figure 4. Haematoxylin and Eosin staining $\times 20$ magnification

Classical seminoma containing seminoma cells with signet ring morphology

Figure 5. IMMUNOSTAINING OF OCT $3 / 4 \times$ 20-magnification

Seminoma cells with signet ring morphology showing positive staining with OCT $3 / 4$
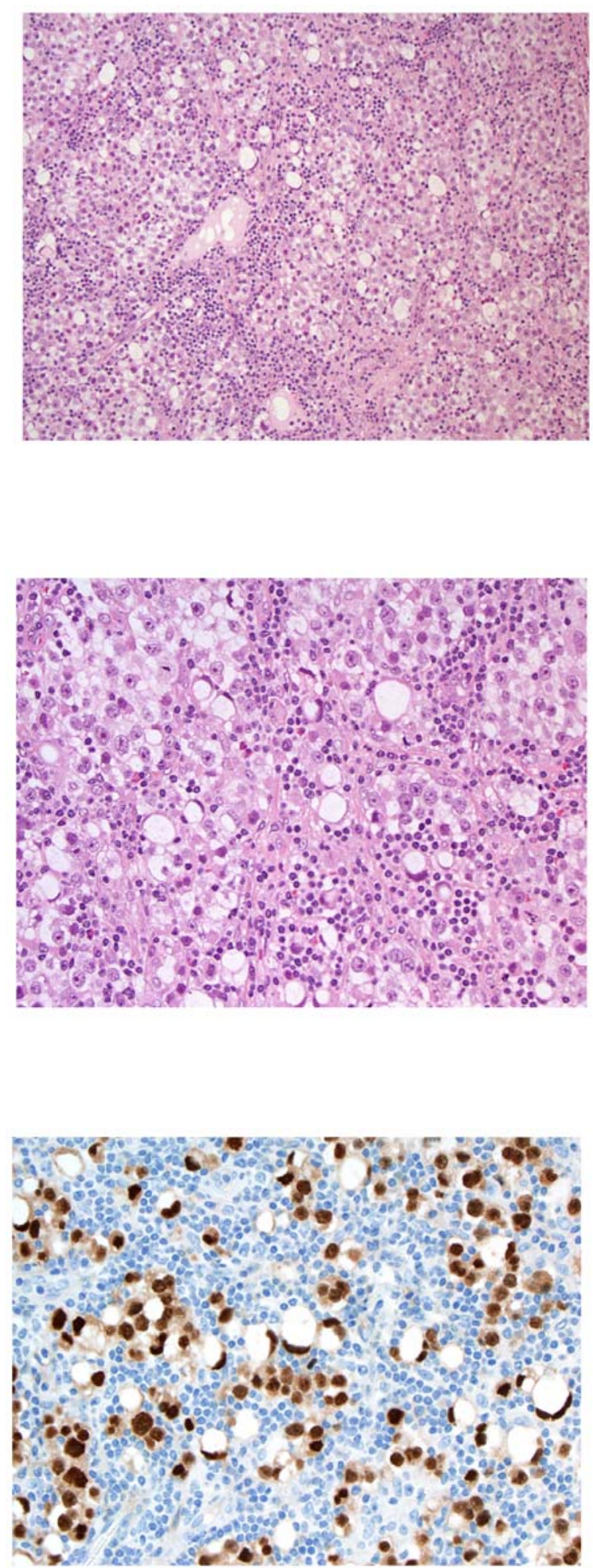
Figure 6. Immunostaining for CD117 × 60-magnification

Seminoma cell with signet ring morphology showing positive staining with CD117

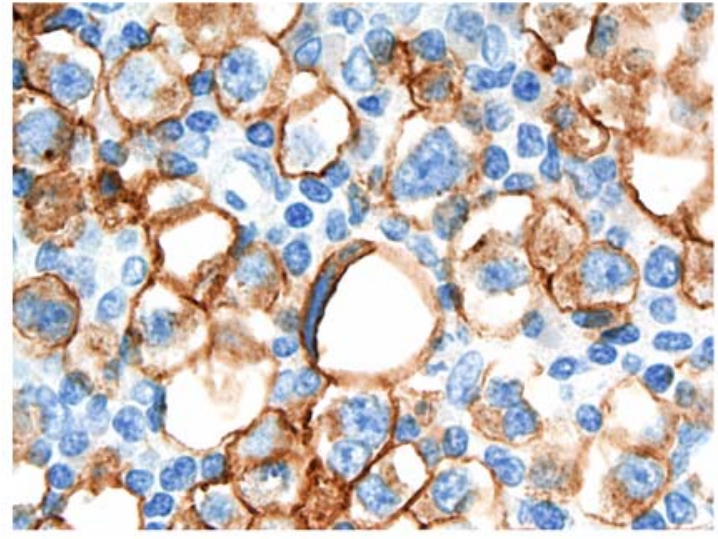

The tumour was further reviewed by the first examining pathologist who reported that:

- The cells with signet-ring morphology were seminoma tumour cells which showed positive immunostaining with OCT 3 / 4 and CD117.

- The cells showed negative staining with AE $1 / 3$ and CD30.

- The nuclei of these cells had been displaced to one side of the cell due to the marked cytoplasmic vacuolation, creating signet-ring appearances.

- The distribution of these cells in the tumour was patchy and constituted less than $5 \%$ of the whole tumour.

- Ninety-five percent (95\%) of the tumour consisted of the classical seminoma tumour cells

Pursuant to the reviewing pathologists report the signet-ring morphology cells were quantified as $5 \%$ of the tumour.

At post-operative follow-up the histological findings were explained to the patient and he was also referred to the Regional Oncology Centre for further management and follow-up for his testicular tumour. In addition he was referred for sperm banking. However, he was found to have azoospermia. At this stage further clinical examination revealed that he had normal right testis. He again had further investigations which were reported as follows:

- Serum follicle stimulating hormone $(\mathrm{FSH})-19 \mathrm{u} / \mathrm{L}$ (normal range $1-10 \mathrm{u} / \mathrm{L}$ );

- $\quad$ Serum luteinising hormone) $\mathrm{LH}-8 \mathrm{u} / \mathrm{L}$ (normal range $1-9$ );

- Serum Prolactin - $271 \mathrm{mu} / \mathrm{L}$ (normal range $50-425 \mathrm{mu} / \mathrm{L}$ );

- Serum Testosterone - $12.1 \mathrm{n}-\mathrm{mol} / \mathrm{L}$ - (normal range [8.7 - 29 n-mol / L]);

Further ultra-sound scan of the right testis which showed microlithiasis in the right testis with no evidence of tumour (see Figure 7):

His follow-up serum Beta Human chorionic gonadotrophin level returned to normal post-operatively.

Based upon the raised serum FSH level it was felt that he may have a degree of failure of his right testis. He has been referred to the Regional Oncology Centre for further management where the possibility of genetic testing would be discussed with him. He is now under the care of the oncologists. 
(a)

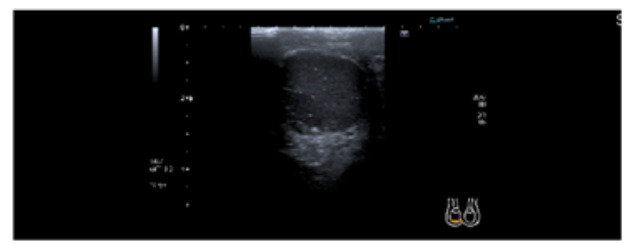

(b)

Figure 7. Two views of repeat ultrasound scan of right testis 3 months post left radical orchidectomy during investigation for azoopermia showing right testicular microlithiasis but no tumour

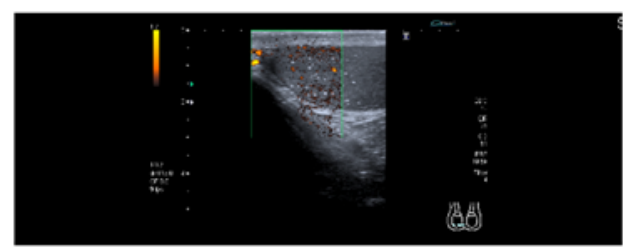

\section{Discussion}

The name signet ring cell was coined because of its appearance which resembles a signet ring. Signet ring cells contain a large amount of mucin, which pushes the nucleus to the periphery. The pool of mucin in a signet ring cell mimics the appearance of a finger hole and the nucleus has the appearance of the face of the signet ring in profile.

Irrespective of the tissue of origin, signet-ring cell carcinomas frequently tend to metastasize to peritoneal surfaces, regional lymph nodes, ovaries, and lungs ${ }^{[11]}$.

Bazan and associates ${ }^{[12]}$ stated that immunohistochemical staining is useful in the determination of the origin and malignant potential of signet ring cells. Gastric signet-ring cell carcinoma is positive for CK7, CK20, and MUC2 and negative for MUC1. Breast signet-ring cell carcinomas are mostly CK7-, MUCI- and oestrogen -positive, and CK20negative. Colon signet-ring cell carcinomas are usually CK20- and MUC2- positive and CK7- and MUC1- negative ${ }^{[4,11,13]}$. Non-neoplastic signet -ring cells exhibit E-cadherin but no p53 mutation ${ }^{[14]}$.

Schaefer and associates ${ }^{[15]}$ reported a 64-year-old patient who complained of right testicular pain. He underwent right-sided orchidectomy, and a diagnosis of metastatic signet ring cell adenocarcinoma of spermatic cord and testis was made based upon histological examination and immunohistochemistry. He had a biopsy of his stomach following this and histology of the biopsy specimen was consistent with primary signet ring cell carcinoma of stomach. They stated that immunohistochemical staining plays an important role in the differential diagnosis of spermatic cord enlargement.

Saredi and associates ${ }^{[16]}$ also reported a testicular metastasis of signet ring cell tumour of unknown origin. Niesel and associates ${ }^{[17]}$ reported two patients with metastatic signet-ring cell carcinoma to the scrotum. They reported 2 patients; one patient whose scrotal metastatic lesion was found to have emanated from an adenocarcinoma of appendix with a signet ring component which had not been apparent clinically; the second was seen at an advanced stage of signet ring cell carcinoma of the sigmoid colon following surgical therapy and palliative chemotherapy in which it was thought that the route of metastases was via seeding along the spermatic cord and via lymphatic dissemination.

Michal and associates ${ }^{[5]}$ reported the first case of signet-ring- stromal- tumour of testis, in a 47-year-old man. They reported that the tumour was located under the tunica albuginea surrounded by the testicular tubules and rete testis. They also noted that the tumour was sharply circumscribed by a thin and irregular capsule. Histological examination showed that the tumour was composed of cells with a wide-spread signet-ring cell change separated by fibrous stroma. In some areas the signet-ring cells formed vague Indian files, hence resembling metastatic carcinoma with signet-ring cell 
morphology. Microscopic examination under high magnification revealed that most of the cytoplasm of the tumour was replaced by an empty clear vacuole which pushed the nuclei to the periphery of the cells. Some of the nuclei were observed to be indented by cytoplasmic vacuoles, others were without indentation. The tumour, in a small area, showed cells without a signet-ring change. The cells looked like epithelioid fibroblasts forming abortive and vaguely tubular structures. There was no evidence of mitosis and necrosis. Mucicarmine and PAS stains were negative. Immunohistochemistry examination of the specimens revealed that the tumour was vimentin positive and negative with antibodies to cytokeratins, inhibin, prostatic acid phosphatase, prostatic-specific antigen, smooth muscle actin, S-100 protein, EMA and calretinin. They observed that the patient was alive and free of recurrence and metastasis 3 years after the excision. Michal and associates ${ }^{[5]}$ concluded that signet-ring stromal tumour of the testis is thus morphologically and immunohistocheniccally similar to the signet-ring stromal tumour of the ovary.

Kuo and associates ${ }^{[18]}$ reported a case of testicular signet-ring stromal tumour with positive immunostain for CD99, which had not been reported previously. They stated that most important differential diagnosis of signet-ring stromal tumour is metastatic signet ring cell carcinoma because of its different management and prognosis. Kuo and associates ${ }^{[18]}$ also said the following:

- Signet-ring stromal tumours have a well-defined growth pattern, bland histological features, no mucin production, and immunoreactions to vimentin, rather than cytokeratin, all of which help pathologists to rule out metastatic adenocarcinoma.

- Even though ovarian signet-ring stromal tumours are categorized in the fibroma/thecoma group of sex cord stromal tumours, the cell origin of signet ring stromal tumours is still debatable.

- The histological criteria for the prediction of clinical behaviour of signet-ring stromal tumours are not clear.

To our knowledge only about 3 cases of seminoma of testis with foci of signet-ring cell morphology have been reported to date and in view of this the biological behaviour of such tumours cannot be well known.

Firstly, Williamson and associates ${ }^{[19]}$ reported a 53-year-old man, whose testicular tumour was found to be composed entirely of signet ring cells, mimicking metastatic carcinoma. They also reported that subsequently retroperitoneal lymph node dissection revealed metastatic deposits composed of teratoma and yolk sac tumour, in addition to signet ring cell carcinoma. Fluorescence in situ hybridization for abnormalities of chromosome 12p revealed the presence of i (12p) in both the teratoma and signet ring cell carcinoma in the metastasis and in signet ring cells in the testis in support of a common germ cell origin. Williamson and associates ${ }^{[19]}$ stated that the development of somatic-type malignancy from a mixed germ cell tumour is a rare but recognized event and typically is represented by sarcoma, or less commonly, by carcinoma. They suggested that this phenomenon results from progression of a teratomatous component as is generally believed. They also stated that in a number of cases because of the intermingling of other germ cell tumour components, the diagnosis is apparent, but, in rare cases, metastatic carcinoma to the testis or a novel primary tumour may be a diagnostic consideration. Williamson and associates ${ }^{[19]}$ concluded that their report indicated that signet ring carcinoma cells in an orchidectomy specimen, although usually strongly suggestive of metastatic adenocarcinoma from a primary tumour in another organ, may be a primary testicular neoplasm of germ cell tumour origin. They also stated that their report was the first report of testicular signet-ring- cell carcinoma of germ cell tumour derivation.

However, Ulbright and Young ${ }^{[20]}$ earlier reported 2 seminomas with conspicuous number of signet ring cells. The tumours were found in men, 24 and 69 years of age, who presented with testicular masses; 1 seminoma was a component of mixed germ cell tumour and the other was pure. The signet-ring-cells occurred in a multifocal fashion in areas of otherwise typical seminoma and comprised approximately $70 \%$ and $10 \%$, respectively, of the tumours. They had large transcluscent to clear cytoplasmic vacuoles that compressed the nucleus to a peripheral crescent. In one case, the vacuoles contained numerous refractile, non polarisable globular deposits that were shown to be glycogen on the basis of periodic acid-schiff stain positivity that was abolished by pre-treatment with diastase; in the second case, they mostly appeared "empty" and 
lacked periodic acid-schiff positivity. The signet-ring-cells were mucarmine, cytokeratin (AE 1/3) and alpha-fetoprotein negative, but positive for OCT 3 / 4 and CD117, the latter two being expected for seminoma cells. Ulbroght and Young ${ }^{[20]}$ reviewed 30 randomly selected seminomas and they identified very rare, inconspicuous signet-ring-cells in $43 \%$. Ulbright and Young ${ }^{[20]}$ stipulated that the presence of prominent signet-ring-cells in seminoma may cause confusion as it has not been described previously in detail, and a variety of neoplasms, particularly metastases may be considered. They concluded that the description of this phenomenon (seminoma with foci of signet-ring-cell morphology) expands the known morphologic spectrum of most common testicular common testicular neoplasm. In all if one takes into consideration the inconspicuous signet-ring-cells that were found in $43 \%$ of 30 seminomas that were alluded to by Ulbright and Young, in their review ${ }^{[20]}$, it would be said that less than 20 cases of signet-ring-cell morphology tumour cells have so far been reported or alluded to in the literature.

In this particular case about $5 \%$ of the seminoma tumour cells had signet-ring morphology and these cells showed positive immunostaining with OCT $3 / 4$ and CD117. In view of the paucity of reported cases of seminoma of testis with signetring-cell morphology, it would be said that the biological behaviour of such tumours has not been clearly ascertained. If seminomas of testis with signet-ring-cell morphology are aggressive tumours there is no information to suggest whether or not the biological behaviour of such tumours would depend upon the percentage of the tumours that have signet-ring morphology. It is also not known whether or not the biological behaviour of such tumours would depend upon the distribution pattern of the signet-ring morphology cells (whether or not the biological behaviour of the tumours would be different for signet-ring morphology cells that are patchily or diffusely distributed is not known).

In view of the rarity of primary seminoma of testis with signet-ring-cell morphology there is minimal knowledge regarding the biological behaviour of this type of carcinoma of testis hence there is no universally accepted treatment strategy for this clinical entity (seminoma of testis with foci of signet-ring-cell morphology). Considering the fact that the biological behaviour of seminoma of testis is known and considering the fact that only about $5 \%$ of the seminoma tumour cells had signet ring-cell morphology in this case the approach to the management should be based upon the management approach to seminomas as suggested by Schmoll and associates ${ }^{[21]}$ on behalf of ESMO guideline working group (Testicular seminoma: ESMO clinical recommendations for diagnosis treatment and follow-up) until the biological behaviour of signet-ring cell carcinomas of testes are established as follows:

\section{(A) Treatment of primary tumour}

Trans-inguinal radical orchiectomy is the standard of care and partial orchiectomy may be performed in specific indications.

Surgery of the primary tumour should be performed before any further treatment, unless there is life-threatening metastatic disease and clear clinical diagnosis of germ cell tumour by marker elevation which requires immediate chemotherapy.

Tumour marker analysis should be performed before surgery and, if elevated, 7 days after surgery to determine the half-life kinetics. Tumour markers should be monitored until normalization. Markers should be taken after surgery, even if normal.

\section{(B) Radical orchiectomy}

Radical orchiectomy should be performed through an inguinal incision. Any scrotal violation for biopsy or open surgery should be avoided strongly. Tumour-bearing testis should be resected with the spermatic cord at the level of the internal inguinal ring. A frozen section is recommended in doubtful cases (of small tumours) before definitive surgery, to allow organ-sparing surgery. 


\section{(C) Organ-preserving surgery/partial orchiectomy}

Radical orchiectomy may be avoided and replaced by organ-preserving surgery; however, only in highly experienced centers and, in particular, in case of synchronous bilateral testicular tumours, metachronous contra-lateral (second) testicular tumour, tumour in a solitary testis and sufficient endocrine function, and contralateral atrophic testis.

After local resection the spared testicular tissue always contains TIN, which can be destroyed by adjuvant radiotherapy. This can and should be delayed in patients who wish to father children, but for a period as short as possible.

\section{(D) Contra-lateral biopsy for diagnosis of TIN}

About $3 \%-5 \%$ of testicular cancer patients have TIN in the contra-lateral testis with the highest risk ( $\geq 34 \%)$ with testicular atrophy (volume $<12 \mathrm{ml}$ ) and age $<40$ years, and in patients with extra-gonadal germ-cell-tumour prior to chemotherapy ( $\geq 33 \%$ ), but only in $10 \%$ post-chemotherapy.

If untreated, invasive testicular tumour develops in $70 \%$ of the TIN-positive-testis within 7 years.

The sensitivity and specificity of one random biopsy for the detection of TIN is very high. Therefore, patients should be informed about the potential risk of TIN and a contra-lateral biopsy should be offered. However, patients themselves should be given the opportunity to decide whether a biopsy should be done or only monitoring performed — assuming the same high level of survival (nearly 100\%) whatever strategy is chosen.

If the patient has had chemotherapy a biopsy should not be taken $<2$ years from treatment.

\section{(E) Treatment of TIN}

If TIN has been diagnosed the options include immediate definitive treatment, surveillance with delayed active treatment or no treatment. The strategy should be chosen by the patient depending on the individual needs, in particular if fertility is an issue. However, fertility potential is often very low in this group of patients. If fertility has to be maintained, definitive treatment should be delayed and substituted by active surveillance until conception followed by either active treatment or further surveillance. If fertility is not relevant, irradiation with 16-20 Gy (2 Gy fraction, 5×/week) [III] should be performed (the strongest evidence is for $20 \mathrm{~Gy}$ ).

In patients with TIN and no gonadal tumour (incidental diagnosis, e.g. by biopsy for infertility or extragonadal germ cell tumours) orchiectomy is preferred over irradiation, because of potential damage to the contralateral, non-affected testis by scattered radiation.

For TIN in patients receiving chemotherapy, chemotherapy eradicates TIN in two-thirds of patients. Therefore, treatment for TIN is only indicated if re-biopsy after chemotherapy is considered; however, not earlier than 2 years after chemotherapy. Instead of definitive treatment for TIN, it is strongly suggested to follow up the patient by monitoring alone, including the possibility of a (re)biopsy.

\section{(F) Treatment of stage I}

About $75 \%$ of patients with seminoma have stage I disease, with a survival of $>99 \%$ independent of the chosen strategy of treatment.

It is most important is to minimize the burden of treatment as much as possible. 
Active (adjuvant) treatment should be avoided and substituted by active surveillance independent of the individual risk for relapse.

\section{(G) Treatment algorithm for seminoma}

The rate of relapse at 5 years is $12 \%, 16 \%$ and $32 \%$ in patients without risk factors, with one risk factor and with two risk factors (tumour size $\geq 4 \mathrm{~cm}$; invasion of the rete testis), respectively.

In $97 \%$, relapse occurs in the retroperitoneal or high iliacal lymph nodes. Late relapse is possible even after 10 years in very rare cases.

A risk-adapted strategy with selection of adjuvant treatment according to the individual risk is currently investigated and still experimental.

With surveillance strategy as standard approach, up to $88 \%$ of the standard patient population does not need any treatment after the local tumour ablation.

Only if surveillance is not applicable, the equally effective alternatives are either adjuvant carboplatin (one cycle, area under the curve 7) or adjuvant radiotherapy (20 Gy in 2 Gy fractions; para-aortic fields)

\section{(H) Radiation doses and fields for early stage seminoma}

Both options deliver the burden of active systemic or local treatment to $100 \%$ of the patients and, in addition, full PEB chemotherapy to $3 \%-5 \%$ of the patients because of relapse after adjuvant treatment. Thus, surveillance offers the lowest burden of overall treatment.

\section{(I) Treatment of stage IIA (lymph nodes 1-2 cm)/borderline IIB (lymph nodes 2-2.5 cm)}

Clinical stage IIA seminoma should be verified beyond standard imaging, for example by needle biopsy, before initiation of systemic chemotherapy.

Standard treatment should include para-aortic and ipsilateral iliac radiotherapy to $30 \mathrm{~Gy}$ in $2 \mathrm{~Gy}$ fractions. Chemotherapy (PEB for three cycles or PE for four cycles, if there are arguments against bleomycin) is an equivalent option with different and more acute toxicities, but probably less risk for secondary cancer.

\section{(J) Treatment of stage IIB (lymph nodes $2.5-5 \mathrm{~cm}$ )}

PEB for three cycles is standard (3- or 5-day schedule). If there are arguments against bleomycin [reduction in lung capacity, emphysema, severe (ex-smokers, etc.) then four cycles of PE are used

For patients refusing or otherwise non-candidates for chemotherapy, para-aortic and ipsilateral iliac field radiotherapy to 36 Gy in 2 Gy fractions is standard.

\section{(K) Treatment of advanced seminoma stage IIC/III}

Chemotherapy with PEB is standard treatment: three cycles for good prognosis patients (3- or 5-day schedule) and four cycles for intermediate prognosis patients (5-day schedule) (see below). 
In case of an increased risk for bleomycin-induced lung toxicity, three cycles PEB in good prognosis patients may be substituted by four cycles PE. In patients with intermediate prognosis the substitution of bleomycin by ifosphamide, without increasing the number of cycles, seems to be an appropriate option

Chemotherapy consists of PEB given as a 5- or 3-day schedule for good prognosis patients and as 5-day schedule for intermediate prognosis patients.

The 5-day schedule is cisplatin $20 \mathrm{mg} / \mathrm{m}^{2}$ (30-60 min), days 1-5; etoposide $100 \mathrm{mg} / \mathrm{m}^{2}$ (30-60 min), days 1-5; bleomycin $30 \mathrm{mg}$ (absolute) bolus, days 1, 8 and 15 . The 3-day protocol is cisplatin $50 \mathrm{mg} / \mathrm{m}^{2}$ (30-60 min), days 1-2; etoposide 165 $\mathrm{mg} / \mathrm{m}^{2}$ (30-60 $\mathrm{min}$ ), days 1-3; bleomycin $30 \mathrm{mg}$ (absolute) bolus, days 1,8 and 15 .

In case of complete response, follow-up only is required. In case of residual tumour $>3 \mathrm{~cm}$, a PET scan (a minimum of 6 weeks after chemotherapy) is recommended, whereas it is only optional in residual lesion $<3 \mathrm{~cm}$ (in lesions $<3 \mathrm{~cm}$ predictive value is less proven).

If PET scan is positive there is strong evidence for residual active tumour and resection should be considered. If PET scan is negative, follow-up only without active treatment is needed. If no PET is done, lesions $>3 \mathrm{~cm}$ can be either resected or followed up only until resolution or progression.

\section{(L) Salvage treatment}

Cases of relapse after radiation of early stages of seminoma

Chemotherapy is the treatment of choice (standard chemotherapy as in stage IIC/ III).

In cases with localized, small volume relapse (re-)irradiation may be considered instead of chemotherapy, in particular if the interval has been long and it is not a disseminated relapse.

\section{(M) Relapse after primary chemotherapy}

Salvage chemotherapy. Relapse after a longer ( $>3$ months) period following initial favourable response does not always represent a platinum-resistant situation. Cisplatin is part of salvage treatment protocols, preferably together with additional agents which have not been used in the first-line treatment. After second-line and, in some cases, also after third-line treatment, chemosensitivity may still be present.

Standard first-line salvage chemotherapy is standard dose VIP, TIP or VEIP. There is no proven benefit of high-dose chemotherapy as for first- or second-line salvage treatment.

In refractory patients, e.g. those who never reach a marker-negative complete response after first-line treatment or have no favourable response after salvage treatment, no standard treatment can be recommended. Gemcitabine/paclitaxel may be considered as an option. High-dose chemotherapy in this setting is largely experimental and should only be performed in clinical trials. Surgery should be part of the strategy, in particular in those patients with localized or late relapse with poor response to chemotherapy. Patients should be included in clinical trials and referred to expert centres whenever possible.

\section{(N) Response evaluation for metastatic disease}

The treatment effect should be monitored by appropriate measures (chest X-ray, CT scan and markers) at 1 month after end of treatment [IV, B]. In case of residual mass a PET scan is recommended [II]. 


\section{(O) Follow-up}

The recommended follow-up schedules are very pragmatic and have never been validated.

Gonzalez Sanchez and associates ${ }^{[22]}$ reported a case of testicular microlithiasis which was incidentally diagnosed by ultrasound scan in a patient who was undergoing evaluation for infertility. They reported that the patient's serum FSH and LH were raised and the serum testosterone was within normal range. Spermiogram revealed azoospermia. Ultra-sound scan of testes revealed bilateral small hyper-echoic foci without posterior acoustic shadowing, dispersed within normal testicular parenchyma. They concluded that: testicular microlithiasis is a rare entity, the underlying condition (calcium in seminiferous duct lumen) has specific ultrasonographic appearance and further studies are not required to make the diagnosis; the pathogenesis and clinical implications of microlithiasis remain unclear, therefore any associated pathology, such as tumour, infertility, systemic diseases, or chromosomal disorders must be ruled out and they recommended that regular follow-up ultrasound scans should be performed.

Sasagawa and associates ${ }^{[23]}$ stated that the influence of testicular microlithiasis on male infertility is unknown. They speculated that the presence of testicular microlithiasis enhances hypospermatogenesis and the prognosis of infertility is compromised in patients with microlithiasis.

Alzenstein and associates ${ }^{[24]}$ speculated that the magnitude of hypospermatogenesis in patients with testicular microlithiasis is variable and may relate to both the degree of testicular dysgenesis and the presence or absence of concomitant scrotal pathology (eg, scrotal varicocele, and cryptorchidism)

Zhang and associates ${ }^{[25]}$ suggested that nanobacteria may be linked to testicular microlithiasis in infertility.

In this particular case the radiologist was able to make a diagnosis of bilateral microlithiasis and a left sided testicular tumour which was diagnosed based upon the ultrasound scan findings to be germ cell tumour / seminoma. To our knowledge testicular microlithiasis has been reported in association with infertility but there is nothing in the literature that has associated seminoma with foci of signet-ring cell morphology with microlithiasis and / or infertility.

The patient who had a family history of testicular cancer and who was aware that an abnormal lump in the testis could be testicular cancer waited for 11 months before seeking medical attention to investigate the lump. Ultrasound scan was useful in establishing the diagnosis and this enabled the patient to agree to undergo a radical orchidectomy. Ultrasound scan and CT scan would continue to feature in the follow-up management of this patient as well as regular measurement of his serum beta human chorionic gonadotrophin (B-HCG) levels in view of the slight elevation of his pre-operative serum HCG level.

Mancini and associates ${ }^{[26]}$ reported their study in which 1443 consecutive infertile men were investigated, out of which $145(10.0 \%)$ of the men were found to be azoospermic. By the use of a combination of clinical examination and testicular ultrasound scan, 11 out of the 145 patients showed testicular nodules (measuring $2.8 \mathrm{~mm}$ to $26 \mathrm{~mm}$ ). In order to obtain spermatozoa for assisted reproduction, 97 of the patients required testicular sperm extraction (TESE) and biopsy, including the 11 patients with nodules. The patients were divided into two groups according to the biopsy results as follows: Group A $(n=38)$ with complete Sertoli-cells only syndrome $(\mathrm{SCOS})$ and group B $(\mathrm{n}=59)$ with varying spermatogenetic patterns. Ten nodules were found in Group A and one in Group B. They found that in azoospermic men, the overall prevalence of nodules was $7.5 \%$ in complete SCOS, the prevalence of nodules and cancer was 10 out of 38 $(26.3 \%)$ and 4 out of $38(10.5 \%)$, respectively. Among the cancers, one embryonal carcinoma, one seminoma and two in-situ carcinomas were found. They concluded that the prevalence of testicular nodules and cancer in azoospermic men with complete SCOS is very high and that in these patients, the role of clinical evaluation, ultrasound scan and testicular biopsy should be emphasized. 
Carmignani and associates ${ }^{[27]}$ reported that between January 2003 and December 2006, thirty-five testicular cancers were diagnosed in their institution. As soon as testicular tumour was diagnosed the patients were requested to cryo-conserve their semen (for sperm banking) before orchiectomy. They reported that over all 20 patients adhered to their recommendation. The remaining 15 patients did not follow-this recommendation only due to strongly personal and psychological reasons. They reported that ten patients were found to have severe oligospermia or azoospermia at the time of the diagnosis of the testicular cancer. Nine months pursuant to the removal of testicular tumours, 9 patients recovered improved their fertility passing from an azoospermic status to having sperm counts of $5.68 \times 10^{6}$ spermatozoa per $\mathrm{ml}$. However, one patient remained azoospermic. They also stipulated that in 1999, Petersen and associates ${ }^{[28]}$ stated that the presence of so many infertile patients at the time of testicular tumour diagnosis is linked with defined genetic alterations in the other testis. These alterations were linked with severe oligospermia. They concluded that their study evidenced how a considerable percentage azoospermic and oligospermic patients recover fertility following definite cancer therapies even if these are potentially harmful for spermatogenesis. With regard to the patient whether or not there would be improvement in his fertility status following his completion of chemotherapy it is only time that would tell.

Petersen and associates ${ }^{[29]}$ analysed the semen quality of men who were diagnosed with unilateral testicular cancer. Petersen and associates ${ }^{[29]}$ reported that the quality of semen which were collected from these men was much poorer than would typically be expected for a man possessing one functional testicle. Carcinoma in situ (CIS) which is a pre-cancerous cellular condition was seen more frequently in the testicular biopsies of men who were evaluated for infertility or infertility by Oleson and associates ${ }^{[30]}$. These findings would strongly indicate that men with fertility problems, even those with undiagnosed sub-fertility, are at an increased risk of developing testicular cancer.

Paul and associates ${ }^{[31]}$ stated that both male infertility and testicular cancer have been associated with SRY gene, DNA repair genes and tumour suppressor gene mutations.

Mutations in the SRY gene linked to gonadal tumour formation and infertility. It has been stated that alterations of the SRY gene are most commonly associated with complete gonadal dysgenesis and patient with these alterations can present with phenotypes ranging from streak gonads such as those seen in Turners syndrome to genital ambiguity. Uehara and associates ${ }^{[32]}$ reported a meta-analysis which noted gonadal tumour formation in $52.5 \%$ of patients with SRY abnormalities

Hughes and associates ${ }^{[33]}$ postulated that supraphysiological levels of reactive oxygen species (ROS) in the semen lead to oxidative damage to the sperm, which may manifest as DNA breakage, cross-linkage and mutation. Recent studies by Hughes and associates ${ }^{[33]}$ depicted that infertile men have high ROS levels in the seminal fluid. Hughes and associates ${ }^{[33]}$ also stated that in addition to causing DNA damage, ROS also results in the production of highly mutagenic compounds that can further increase an individual's susceptibility to tumour formation.

It has been postulated by Deviguassou-Shisheboran and associates ${ }^{[34]}$ that chronic oxidative damage is indicative of a deficiency in DNA repair mechanisms. They also postulated that mutations in these genes can result in deletions or expansions of small repair DNA sequences, leading to unstable components that have been noted in many terms of cancer. In addition they stated that, furthermore, these mutations and expansions of DNA repeat sequences can manifest as male infertility.

It has been stated that cases of male infertility and cancer formation have also been attributed to deficiencies in tumour suppressor genes, particularly P53 ${ }^{[35]}$. The P53 gene plays a crucial role in tumour prevention and stress response pathways. P53 also helps to coordinate a variety of cellular responses from cell cycle arrest and apoptosis to the maintenance of genomic stability. This gene also has an important role in spermatogenesis-specifically during the prophase of meiosis within primary spermatocytes. Mutations result in in chromosomal and genomic instability, increasing the chance that P53-null cells will become malignant and gain additional mutations ${ }^{[36,37]}$. This genomic instability would also compromise the sperm's ability to fertilize an egg ${ }^{[35]}$. It has also been reported that P53 has a role in 
the up-regulation of certain anti-oxidant genes ${ }^{[37]}$. A knock out of this gene would thus leave the cell without an important defence against ROS. Therefore at high ROS levels, such as those seen in infertile patients, the cell would be susceptible to an even greater amount of oxidative stress and subsequent DNA damage.

\section{Conclusions}

There is paucity of literature on primary testicular tumours with signet-ring morphology. In order to establish the biological behaviour of such tumours we would encourage pathologists and urologists to report cases of testicular tumours associated with signet-ring-cell morphology together with the long term biological behaviour of such tumours. They should also report on the percentage of testicular tumours that have signet-ring-cell morphology as well as their distribution whether patchy or diffuse.

Ultrasound-scan of testis was required to establish the diagnosis of testicular cancer in the patient. Ultrasound-scan of testis is useful in the investigation of a testicular lump. Ultrasound and CT scans are also useful for the follow-up of patients with testicular cancer and microlithiasis.

\section{References}

[1] Cancer Research UK. Signet Ring Cancer [Internet]. Cancerhelp.org.uk URL. Available from: http://www.cancerhelp.org.uk/help/default.asp?page=7581.

[2] Leong F J, Leong A S, Swift J. "Signet-ring carcinoma of the prostate". Pathol Res. Pract. 1996; 192(12): 1232-1239: discussion $1239-1241$.

[3] Jain V, Gupta K, Kudva R, Rodrigues G S. A case of ovarian metastasis of gallbladder carcinoma simulating primary ovarian neoplasm: diagnostic pitfalls and review of literature". Int. J. Gynecol. Cancer. 2006; 16 Suppll 1: 319-321.

[4] Makino T, Tsujinaka T, Mishima H, Ikenaga M, Sawamura T, Nakamori S, Fujitani K, Hirao M, Kashiwazaki M, Masuda N, Takeda M, Mano M. Primary signet ring cell carcinoma of the colon and rectum: report of eight cases and review of 154 Japanese cases. Hepatogastroenterology. 2006; 53: 845-849.

[5] Michal M, Ondrej H, Dmitry V K. "Primary signet-ring stromal tumor of testis". Virchows Archiv. 2005; 447(1): 107-110. PMid:15909171 http://dx.doi.org/10.1007/s00428-005-1218-2

[6] El-safadi S, Stahl U, Tinnerberg H R, Hackethal A, Muenstedt K. Primary Signet Ring Cell Mucinous Ovarian carcinoma: A Case Report And literature Review. Case Report Oncol. 2010 Sep-Dec; 3(3): 451-456. PMid:21611142 http://dx.doi.org/10.1159/000323003

[7] Khoramnia R, Mayer C, Glaser E, Weirich E. Primary signet ring cell carcinoma of the eyelid in a young woman. Eye. 2011; 25: 1380-1382. PMid:21738227 http://dx.doi.org/10.1038/eye.2011.163

[8] Requena L, Priesto V G, Requena C, Sarasa J L, Manzano R, Seco M, Cerroni L, Kutzner H. Primary signet-ring cell/histiocytoid carcinoma of the eyelid: a clinicopathologic study of 5 cases and review of the literature. Am J Surg Pathol. 2011 Mar; 35(3): 378-391. PMid:21317710 http://dx.doi.org/10.1097/PAS.0b013e318209cac7

[9] Lee W S, Chun H K, Lee W Y, Yun S H, Cho Y B, Yun H R, Park S H, Song S Y. Treatment outcomes in patients with signet ring cell carcinoma of the colorectum. Am J Surg. 2007; 194 (3): 294-298. PMid:17693269 http://dx.doi.org/10.1016/j.amjsurg.2006.12.041

[10] Cabebe E C, Mehta V K, Fisher G. Gastric Cancer. eMedicine.com 2007 Nov 8. Available from: http://www.emedicine.com/med/topic845htm.

[11] Panic I, Marusu Z, Mijic A: A case of signet ring cell carcinoma of gall bladder: Immunohistochemistry and differential diagnosis. Acta Chi Croat. 2010; 49: 159-162.

[12] Bazan F, Sanchez J, Aguilar G, Radosevic A, Busto M, Zaccaino F, Pijwen L, Risuenö N. Metastatic gallbladder adenocarcinoma with signet ring cells: A case report. Journal of Medical case Reports. 2011; 5: 458. PMid:21917161 http://dx.doi.org/10.1186/1752-1947-5-458

[13] Tian M, Zhao A L, Li Z, Li J. Phenotypic classification of gastric signet ring cell carcinoma and its relationship with clinicopathologic parameters and prognosis. World J Gastroenterol. 2007; 13: 3189-3198. PMid:17589897

[14] Wang K, Weinrach D, Lal A, musunuri S, Ramirez J, Ozer O, Keh P, Rao M S. Signet ring cell change versus signet ring cell carcinoma: a comparative analysis. Am J Surg pathol. 2003; 27; 1429-1433. PMid:14576475 http://dx.doi.org/10.1097/00000478-200311000-00004

[15] Schaefer I M, Sauer U, Liwocha M, Schorn H, loertzer H, Füzesi L. Occult gastric signet ring cell carcinoma presenting as spermatic cord and testicular metastases: "Krukenberg tumor" in a male patient. Pathol Res Pract. 2010 Jul 15; 206(7): 519-521. PMid:20399569 http://dx.doi.org/10.1016/j.prp.2010.02.006 
[16] Saredi G, Rivalta M, Sighinolfi M C, Rossi G, Fidanza F, Guarasci C, Cesinaro A M, Maria N D, Stafani S D, Bianchi G. Testicular metastasis of signet ring cell tumour of unknown origin: diagnostic features of a tricky case. Andrologia. 2011 June; 43(3): $22-223$. PMid:21486397 http://dx.doi.org/10.1111/j.1439-0272.2010.01048.x

[17] Niesel T, bohm J, Paul R, Breul J,hartung R. Rare metastases of signet ring cell carcinoma to the scrotum: report of two cases. Urology. 1996 May; 47(5): 769-771. http://dx.doi.org/10.1016/S0090-4295(96)00023-4

[18] Kuo C Y, Wen M C, Wang J, Jan Y J. Signet-ring stromal tumor of the testis: a case report and literature review. Hum Pathol. 2009 Apr; 40(4): 584-587. PMid:18835626 http://dx.doi.org/10.1016/j.humpath.2008.07.012

[19] Williamson S, Kum J, Shah S R, Eindhorn L H, eble J N,Cheng 1, Ulbright T, Idrees M. Signet Ring Cell carcinoma of the Testis: Clinicopathologic and Molecular Evidence for Germ Cell tumor Origin- A Case Report. Am J Surg Pathol. 2012 Feb; $36(2)$ : 311 -315. PMid:22251944 http://dx.doi.org/10.1097/PAS.0b013e31823fb7f2

[20] Ulbright T M, Young R H. Seminoma with conspicuous signet ring cells: a rare, previously uncharacterized morphological variant. Am J Surg Pathol. 2008 Aug; 32(8): 1175-1181. PMid:18580681 http://dx.doi.org/10.1097/PAS.0b013e31816597b0

[21] Schmoll H J, Jordan K, Huddart R, Laguna M P, Horwich A, Fizazi K, Kataja V. Annals of Oncology $2009 ; 20$ (Suppl 4): iv 83 - iv 88

[22] Gonzalez Sanchez F J, Encinus Gasper M B, Napel Lecumberri S. Testicular microlithiasis associated with infertility. Arch Esp Urol. 1997 Jan-Feb; 50(1): 71-74. PMid:9182495

[23] Sasagawa I, Nakada T, Kazama T, Satomi S, Katayama T, Matuda S. testicular microlithiasis in male infertility. Urol Int. 1988; 43: 368-369. PMid:3238835 http://dx.doi.org/10.1159/000281397

[24] Alzenstein R I, DiDomenico D, Wilbur A C, O’Neil H K. Testicular Microlithiasis: Association with Male Infertility. J Clin Ultrasound. 1998; 26: 193-198.

[25] Zhang Q H, Lu G S, Shen X C, Zhou Z S, Fang Q, Zhang X, Li L K, Jin X Y, Song B. Nanobacteria May Be linked to Testicular Microlithiasis in Infertility. Journal of Andrology. 2010 March-April; 31(2): 121-126. PMid:19779212 http://dx.doi.org/10.2164/jandrol.109.007930

[26] Mancini M, Carmignani L, Gazzono G, Sagone P, Gadda F, Bosari S, Rocco F, Colpi G M. High prevalence of testicular cancer in azoospermic men without spermatogenesis. Human Reproduction. 2007; 22(4): 1042-1046. Doi:10.1093/hum rep/del1500

[27] Carmignani L, Gadda F, Paffoni A, Bozzini G, Stubinsky R, Picozzi S, Rocco F. Azoospermia and severe oligospermia in testicular cancer. Arch Ital Urol Androl. 2009 Mar; 81(1): 21-23. PMid:19499754

[28] Petersen P M, Givewercman A, Hansen S W et al. Impaired testicular function in patients with carcinoma-in-situ of testis. J Clin Oncol. 1999; 17: 173-179. PMid:10458231

[29] Petersen P M, Skakkebaek N E, Giwercman A. Gonadal function in men with testicular cancer: biological and clinical aspects. APMIS. 1998; 106: 24 - 34. Discussion 34 - 36

[30] Oleson I A, Hoell-Hansen C E, Skakkebaek N E, et al. Int J Androl. 2007; 30: 406-411. Discussion 412

[31] Paul C, povey J E, Lawrence M J et al. Deletion of genes implicated in protecting the integrity of male germ cells has differential effects on the incidence of DNA breaks and germ cell loss. Plos Onc. 2007; 2:e989. PMid:17912366 http://dx.doi.org/10.1371/journal.pone.0000989

[32] Uehara S, Hashiyada M, Sato K, et al. Complate XY gonadal dysgenesis and aspects of the SRY genotype and gonadal tumor formation. J Hum Genet. 2002; 47: 279-284. PMid:12111377 http://dx.doi.org/10.1007/s100380200040

[33] Hughes C M, Lewis S E, McKelvey-Martin VI, Thompson W A. Comparison of baseline and induced DNA damage in human spermatozoa from fertile and infertile men, using a modified comet assay. Mol Hum Reprod. 1996; 2: 613-619. PMid:9239674 http://dx.doi.org/10.1093/molehr/2.8.613

[34] Devguassou-Shisheboran M, Mauduit C, Bouvier R, et al. Expression of hMLH1 and hMSH2 and assessment of microsatellite instability in testicular and mediastinal germ cell tumours. Mol Hum Reprod. 2001; 7: 1099-1105. http://dx.doi.org/10.1093/molehr/7.12.1099

[35] Agarwal A, Burns W R, Dada R, Sabanegh Jr, E S. Male Infertility and Testicular Cancer Patients of Common Causality. European Urological Review. 2010 Sep 15; 5(1): 56-59

[36] Fenton R G, Longo D L. Cancer cell biology and angiogenesis. In Fauci A S, Braunwaid E, Kasper D L, et al. (eds). Harrison's Principles of internal Medicine. 17th edn, McGraw-Hill 2008.

[37] Tourtellotte W G, Nagarajan R, Auyeung A, et al. Infertility associated with incomplete spermatogenic arrest and oligospermia in Egr4-deficient mice. Development. 1999; 126: 5061-5071. PMid:10529423 